\title{
The Students' Limitations in Solving a Problem with the Aid of GeoGebra Software: A Case Study
}

\author{
Le Viet Minh Triet ${ }^{1}$, Nguyen Phu Loc ${ }^{2, *}$ \\ ${ }^{1}$ Department of Mathematics, Ho Chi Minh City University of Education, Vietnam \\ ${ }^{2}$ School of Education, Can Tho University, Vietnam
}

Received April 27, 2020; Revised May 21, 2020; Accepted June 26, 2020

\section{Cite This Paper in the following Citation Styles}

(a): [1] Le Viet Minh Triet, Nguyen Phu Loc, "The Students' Limitations in Solving a Problem with the Aid of GeoGebra Software: A Case Study," Universal Journal of Educational Research, Vol. 8, No. 9, pp. 3842 - 3850, 2020. DOI: 10.13189/ujer.2020.080907.

(b): Le Viet Minh Triet, Nguyen Phu Loc (2020). The Students' Limitations in Solving a Problem with the Aid of GeoGebra Software: A Case Study. Universal Journal of Educational Research, 8(9), 3842 - 3850. DOI: 10.13189/ujer.2020.080907.

Copyright $(\mathcal{O} 2020$ by authors, all rights reserved. Authors agree that this article remains permanently open access under the terms of the Creative Commons Attribution License 4.0 International License

\begin{abstract}
Currently, there is much dynamic math software. They help to provide the user with an intuitive mathematical environment. Also, thanks to the dynamic properties of the software, users can flexibly change mathematical forms and objects by pressing and dragging. Therefore, they have multiple opportunities for surveying, predicting, illustrating, or finding strategies for solving mathematical problems. GeoGebra software is used in this study to find strategies for solving a problem, as GeoGebra integrates and serves many math disciplines. Concerning the math studies solving a problem with GeoGebra's support, this paper devotes particular attention to using Polya's four-step process to a problem. It is a generalized scheme that can be applied to find solutions for all kinds of mathematics. The issue is how to exploit the strength of this dynamic math software if we use this scheme to find strategies for solving a problem. Our research content is to answer the questions: 1) How do students approach solving a math problem with the GeoGebra software? 2) What students' mistakes or limitations can occur? Experimental research results with six student groups have shown that students have made some mistakes with GeoGebra in math problems and they do not know how to take advantage of this software to make it easier to find a solution to the problem. Based on the findings, we suggest several measures to show teachers and students how GeoGebra is used effectively.
\end{abstract}

Keywords Problem-solving, Educational Technology, GeoGebra, Problem-solving Strategy, Dynamic
Mathematics Software, Polya's Four-step Process

\section{Introduction}

\subsection{The Conception of the Problem - Solving}

Developing problem-solving ability for high school students is one of the goals of any education system in the world. According to Loc [9], problem-solving consists of three components; that is problem-determining, problem-solving process; and results obtained (see Table $1)$.

Table 1. The components of problem - solving [9]

\begin{tabular}{|c|c|c|}
\hline Problem & Process of solving & Results \\
\hline $\begin{array}{l}\text { Determine } \\
\text { the goals to } \\
\text { be achieved } \\
\text { (Questions to } \\
\text { be answered) }\end{array}$ & $\begin{array}{ll}\text { - } & \text { Analyze } \\
\text { problems; }\end{array}$ & $\begin{array}{l}\text { The solution to the } \\
\text { problem } \\
\text { Other results: } \\
\text { Gain experience in } \\
\text { solving problems; } \\
\text { Give the general } \\
\text { form of the problem; } \\
\text { Develop conceptual } \\
\text { knowledge or } \\
\text { process knowledge; } \\
\text { Develop student } \\
\text { thinking }\end{array}$ \\
\hline
\end{tabular}

Discussing the role of problem-solving in school 
education, Adoğdu, M. and Ayaz, M. F. [1] states that problem-solving is more than a tool for teaching and mathematical knowledge, and supporting to overcome daily challenges. Problem-solving encourage the student to undergo a variety of emotions associated with various phases of the solution process. According to the National Council of Teachers of Mathematics [10], problem-solving plays a significant role in teaching mathematics in schools, and this organization recommends that the mathematics curriculum should be organized around problem-solving, focusing on:

- Developing skills and adapting those skills to new situations;

- Collecting, setting up, processing and sharing information;

- Formulating critical questions, analyzing and understanding problems, determining problems and objectives, identifying patterns and similarities, searching for relevant data, experimenting, transferring skills and strategies to various situations;

- Creating curiosity, confidence and openness.

\subsection{Why GeoGebra?}

For decades past, educational technology has been promoted in most countries around the world. Regarding the importance of Technology, NCTM states that technology is essential to teaching and studying mathematics; that it affects mathematics that is learned and trains student learning. Teachers can use technology to enhance learning experiences for their students by gathering or designing mathematical activities that take advantages of what technology can do [11]. In the field of teaching mathematics, teaching mathematics with the help of dynamic math software is now considered as one of the modern and practical approaches. According to Haciomeroglu and Janet, dynamic software enhances the comprehension of mathematics among students; students could investigate and make conjectures, and thus have better overall results [4]. Doğan and Içel [3] study the influence of GeoGebra on the achievements of eighth-grade students in triangle subjects; the findings show that dynamic software GeoGebra has significant influences on students' learning and achievements. It has also been noted to increase student engagement positively. In the research of Shadaan and Eu (2013), GeoGebra software has proven to be a useful tool for improving the teaching and learning of mathematics, particularly in learning circles [13]. Participants have been able to experience a practical learning approach that has had a beneficial impact on helping them to grasp the ideas rather than merely being passive learners. In Vietnam, some authors carried out studies on embracing GeoGebra into teaching mathematics, and the findings demonstrated that Geogebra helps improve learning efficiency and students' activeness in the teaching process [8].
Despite much dynamic mathematical software is currently introduced; we decide to choose GeoGebra to study because of the strengths as listed below:

- GeoGebra is a dynamic mathematics software that incorporates dynamic geometry, algebra, calculus, and spreadsheet functions (which other software handles separately) into a single, easy-to-use application [7].

- GeoGebra can help students understand experimental, problem-oriented and research-oriented mathematics learning, both in the classroom as well as at home.

- With GeoGebra, students can use a computer algebra system and an interactive geometric system simultaneously, thus enhancing their cognitive abilities in the possibly best way [2].

- GeoGebra software has proved to be a powerful tool to help teachers and students in the mathematics classroom implement the principles of constructivist learning [14].

According to Herceg and Herceg [6], by reducing students' time to spent and waste on solving mathematic problems by hands, GeoGebra is said to be useful and beneficial for students who find it challenging to solve mathematical problems. Regard how to use GeoGebra in solving math problems and teaching math problems

\section{Research Problem and Questions}

It is clear that the key objective in the Polya's problem-solving process [13] is to find a strategy to solve a problem. In order to obtain this objective, the solver does many things like analyzing data, connecting them, making predictions, and using different approaches to the problem. One issue is that with GeoGebra's support, how to find a problem-solving strategy? To solve this issue, we conducted a study with the following questions:

1. How do students approach solving a mathematics problem with the aid of GeoGebra software?

2. What students' mistakes or limitations can occur?

\section{Methodology}

To obtain a research purpose, we conduct an educational experiment. We use the method of analyzing student work results to identify the difficulties and limitations of students in the process of solving math problems with the help of GeoGebra.

The study is designed to cover the following phases:

- Pedagogical experiment: Asked students solve a problem with GeoGebra 's help to learn how students perform in the problem - solving process. The solutions to the problem at this stage are those of the students themselves; the teacher had no intervention in their math problem solving. 
- $\quad$ Analyzing student work outcomes: Based on Polya's four-step problem-solving process, we analyze how students solve the problem to identify student limitations

- Implications: From the student's constraints, we improve how to apply Polya's math problem-solving process [12] in the case of GeoGebra support and how to analyze and find solving strategies from predictions given GeoGebra

- Illustration: To clarify what is in stage 3, we present two illustrative examples in which the strategies presented in each example were our recommendations.

\subsection{Educational Experiment}

Participants: 12 students who participate in this research are currently studying at grade $11^{\text {th }}$ at Ly Tu Trong High School and Phan Ngoc Hien High School, Can Tho City. They are good at Geometry and can operate GeoGebra quite well because they learnt about this software since their junior school years.

Working in pair: Participants are divided into six groups. They are Group 1, Group 2, Group 3, Group 4, Group 5, Group 6. Each group has a computer to use GeoGebra to solve the task in 45 minutes.

The task for all groups is to solve the following problem:

The problem 1 [5]: "Given a triangle $\mathrm{ABC}$. Construct squares $A B E F$ and $A C I K$ outside the triangle. Let $M$ be the midpoint of side $B C$.

- $\quad$ Determine the relationship between $A M$ and $F K$

- Compare the length of segment $A M$ and the length of FK."

Experimental time: Pedagogical experiment is carried out at the beginning of the second semester of the 2019-2020 school year.

\subsection{Analyzing Students' Work Results}

To detect students' shortcomings and limitations through studying student's works, we follow Polya's four-step problem-solving process [12].

Step 1: Understanding the problem;

Step 2: Devising a solving plan;

Step 3: Carrying out the plan;

Step 4: Look back.

Moreover, from the results, we propose how to effectively apply this process to solve problems with GeoGebra's assistance and use the problem one mentioned above and the following problem 2 to illustrate.

The problem 2: In the plane with the coordinate system Oxy, give the quadrilateral $\mathrm{ABCO}$ with $\mathrm{A}(1 ; 3), \mathrm{B}(3 ; 4), \mathrm{C}$ $(4 ; 0)$ and $O(0 ; 0)$. Determine the coordinates of the point $\mathrm{M}$ on the Ox axis with positive horizontal coordinates such that the triangle $\mathrm{AMO}$ and quadrilateral $\mathrm{ABCO}$ have the same area.

\section{Work Results of Students and Discussions}

The results of solving the students' experimental problems (the 1st problem) in groups as follows.

Group 1(Figure 1)

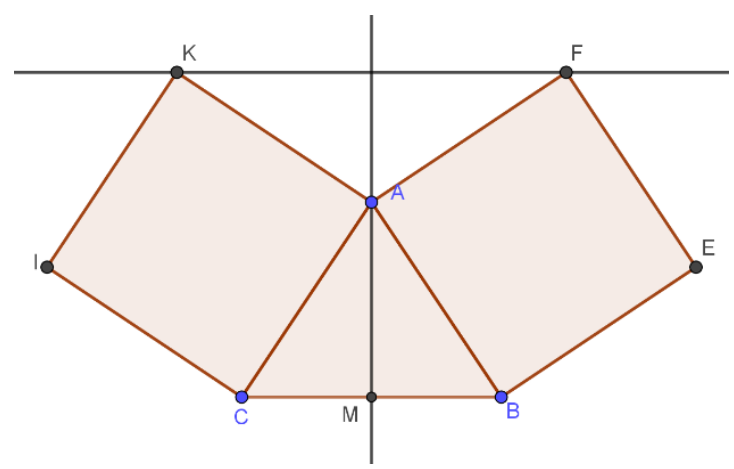

Figure 1. The representative figure of Group 1

- Construct $\mathrm{ABC}$ as an isosceles triangle at $\mathrm{A}$

- Formulate the conjectures: Using Geogebra's functional tool, construct $H$ as the intersection of $A M$ and $F K$ and measure angles created by $A M$ with $F K$. Find that $A M$ is perpendicular to $F K$

- Compare length measurements of $A M$ and $F K$. Students identify that $\mathrm{FK}=2 \mathrm{AM}$

3. Find how to prove $A M$ perpendicular to $F K$ and $F K=$ $2 A M$.

Since the triangle $\mathrm{ABC}$ was defaulted to be an isosceles triangle, they can easily show that AM is perpendicular to $F K$. However, they cannot prove $F K=2 A M$

Comments: The given problem is that the triangle $A B C$ is any triangle, not the isosceles triangle. Therefore, the solution is not accepted. It can be said that students do not understand the problem.

\section{Group 2 (Figure 2)}

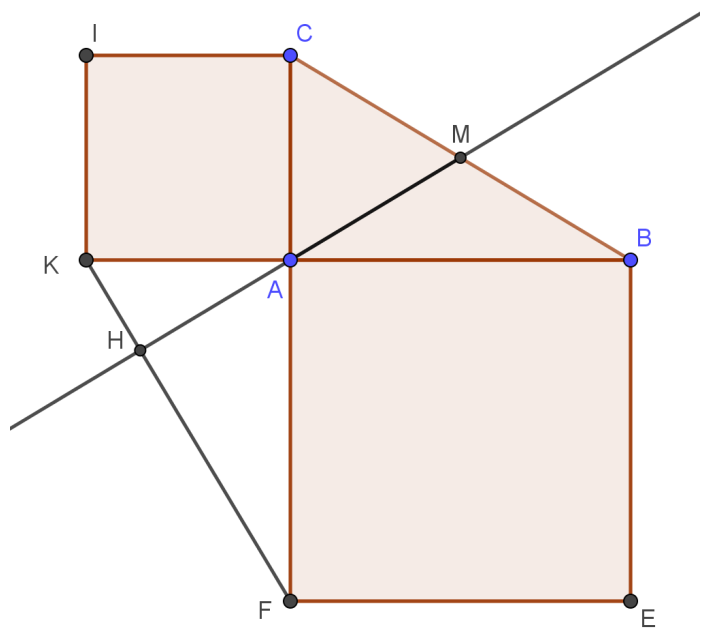

Figure 2. The representative figure of Group 2 
- $\quad$ Construct $A B C$ as a right triangle at $A$, and

- $\quad$ Construct a line $A M$ intersecting $F K$ at $H$

- $\quad$ Measure the angle created by AM with $F K$ and find that $A M$ is perpendicular to $F K$. Compare $A M$ and FK, they found $F K=2 A M$ (by using GeoGebra)

- $\quad$ Proof: Since the $A B C$ triangle was defaulted to be a right triangle, they can easily show that $A M$ is perpendicular to $F K$.

Comments: The group solves the problem in the case that the triangle $A B C$ is a right triangle. Therefore, the solution does not satisfy the requirements of the given problem. Similar to group 1, students in group 2 did not understand the problem.

Group 3 (Figure 3)

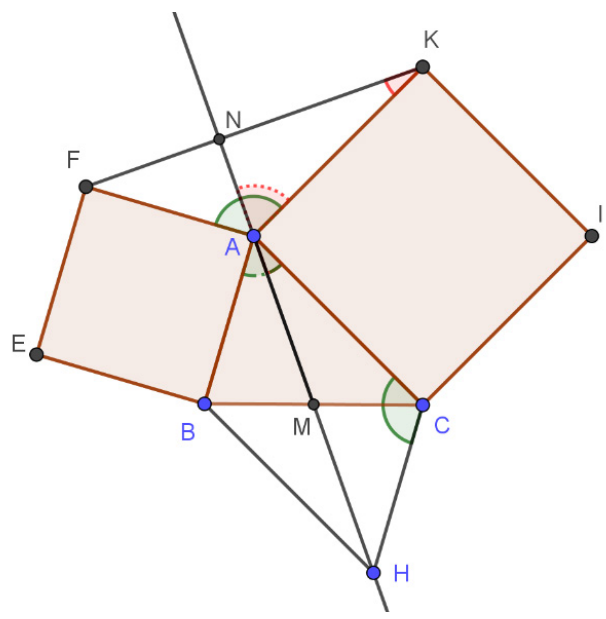

Figure 3. A representative figure of Group 3

- $\quad$ Construct $A B C$ triangle, construct a line $A M$ so that it intersects $F K$ at $N$

- $\quad$ Measure the angle created by $A M$ with $F K$. The result is found that $A M$ is perpendicular to $F K$.

- $\quad$ Proving that $A M$ is perpendicular to $F K$.

Using GeoGebra's tool for measuring angles, students find that $\angle F K A=\angle C A H$

In order to prove $\angle F K A=\angle C A H$, they construct a point $\mathrm{H}$ symmetric to point $A$ through $M$. Construct an $A B H C$ parallelogram.

Thanks to proving that $\triangle F A K=\triangle H C A$; therefore, $\angle F K A=\angle C A H$.It implies $\angle F K A+\angle N A K=90^{\circ}$ or $A N$ $\perp F K$

$$
\left(\angle A N K=90^{\circ}\right) \text {. }
$$

Comments: Thanks to GeoGebra, the team discovers that $\widehat{F K A}=\widehat{C A H}$. Therefore, if this can be proved, the AMK can be deduced by 90 degrees. This information is essential so as that the students solved the problem. It can be said that students do understand the problem and know how to devise and carry out the plan of solving a problem.

\section{Group 4 (see Figure 4)}

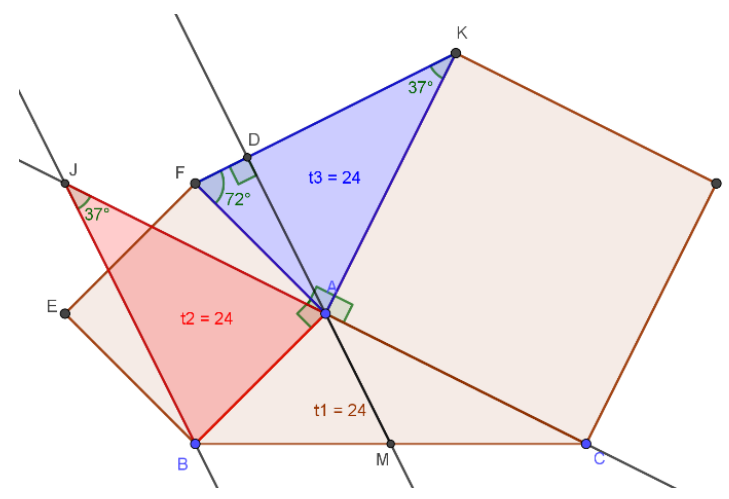

Figure 4. A representative figure of Group 4

Similar to groups 1,2 , groups 4 also predicts that $A M$ perpendicular to $F K$ and $F K=2 A M$.

To test the two hypotheses, the group considers two cases.

To test the two hypotheses, the group considers two cases: The first case of $\angle B A C$ being an acute angle and the second case of $\angle B A C$ being an obtuse angle.

After a search process in different ways, finally, for both two cases, the team finds a solution strategy: draw a line $n$ through B and parallel to AM, the line (n) cuts extending $C A$ at $J$. They prove that the triangles BAJ and FAK are equal. From there, by comparing the angles, they prove that AM is perpendicular to $F K$.

Comments: It is rather challenging for this group to find a strategy to solve this problem because they do not know where to start to find a solution strategy. After the process of searching quite hard, they have found a way to solve the problem. In short, this group understands the problem but met difficulties in devising a plan of solving the problem.

\section{Group 5 (Figure 5)}

Like other groups, group 5 draws a figure to show the problem and predict the $A M$ perpendicular to $F K$ and $F K=$ $2 A M$. Let $\mathrm{H}$ be the intersection of $A M$ and $F K$. This group has analyzed and found a good solution that to prove the angle of $\mathrm{AHF}$ is right, just prove $\angle A F K+\angle H A F=90^{\circ}$. Since, $\angle M A B+\angle H A F=90^{\circ}$ so it is necessary to show $\angle A F H=\angle M A B$.

Then, they draw a straight line (n) passing through $B$ and parallel to $A C$, (p) passing through $C$ and parallel to $A B$. They cut at D. With this construction; the group can prove that $\mathrm{ABDC}$ is a parallelogram and two triangles $A B D$ and $K A F$ are equal. From these, they inferred that $\angle B A D=\angle A F K$ and $F K=A D=2 A M$. Hence, the answers to the problem are: $A M \perp F K$ and $F K=2 A M$ 


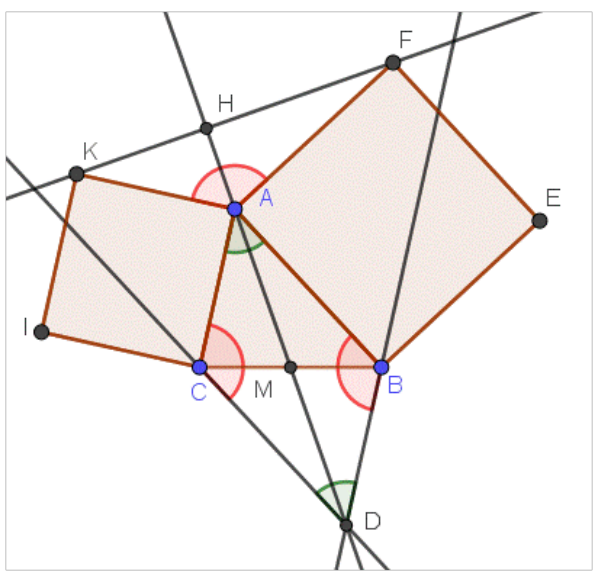

Figure 5. The representative figure of Group 5

Comments: This group already knows how to use backward analysis to find solutions. Thanks to that, the students know what is the starting point to solve problems. As a result, students quickly complete the solution to the problem. It could be asserted that this group has done well the first three steps of the Polya process

Group 6 (Figure 6)

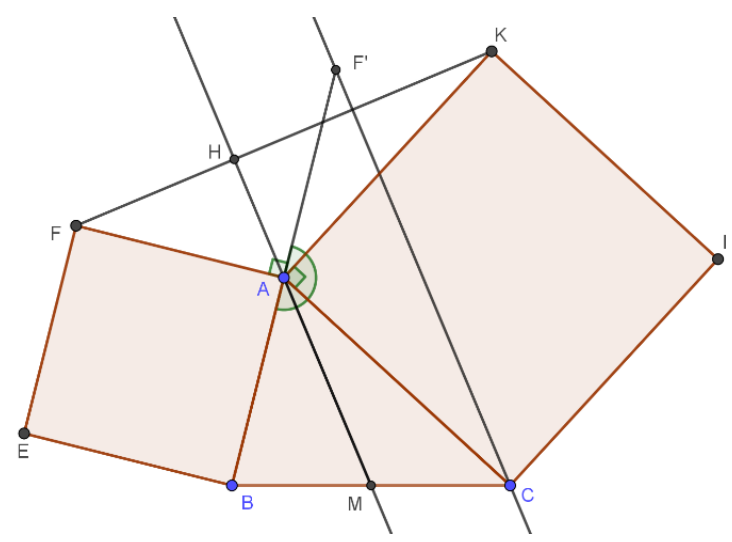

Figure 6. The representative figure of Group 6

With the aid of GeoGebra, this group also predict that the $A M$ perpendicular to $F K$ and $F K=2 A M$.

They apply the rotation of A and the angle $\left(-90^{\circ}\right)$ :

- $\quad$ Mapping point $\mathrm{K}$ onto point $\mathrm{C}$

- Mapping point $\mathrm{K}$ onto point $\mathrm{F}$,

Hence, $F^{\prime} C=F K$ and $\mathrm{F}^{\prime} \mathrm{C} \perp \mathrm{FK}$

Besides, $\mathrm{B}, \mathrm{A}, \mathrm{F}$ ' are colinear and $\mathrm{BA}=\mathrm{BF}$ '. Thus, $\mathrm{AM}$ is the midsegment of the triangle $\mathrm{BCF}$ '. It implies $A M=1 / 2$ $F^{\prime} C$ and $A M / / F^{\prime} C$.

Concluding, $\mathrm{AM}=1 / 2 \mathrm{FK}$ and $\mathrm{AM} \perp \mathrm{FK}$.

Comments: By observing the intuitive representation of the problem, students know how to choose the rotation of centre $A$ and the angle $\left(-90^{\circ}\right)$ to solve the problem. This is a strategy that requires students' ability to apply a transformation to solve the problem. This group solves the problem in a relatively short time. However, this group has some limitations as follows:

- $\quad$ They are not actively thinking, analyzing the visual data of the problem to find other strategies to solve the given problem,

- $\quad$ They are not trying to expand the math problem solved.

\section{Limitations of Students and Implications}

\subsection{The Limitations of Students}

The results of the groups' work show that students have the following mistakes and difficulties in processing the problem with the aid of GeoGebra:

- The solution is only correct for some specific cases but not for general cases. For example, group 1 solves the problem in the case of an isosceles triangle, while group 2 considers the triangle $A B C$ to be a right triangle. Such errors occur because they do not know how to use GeoGebra to consider whether their current conjectures are valid for the various problem cases.

- Students are quite confused about how to start to find strategies to solve a problem when predicting the answer (Group 3, 4,5). The researchers note that, with the support of dynamic mathematic software such as GeoGebra, almost solvers could know the results of the problem in advance. Therefore, the method of backwards analysis (from the results, we infer in the opposite direction to find solving strategies) is dominant in finding the solution strategy for a problem. Teachers need to train students to apply this approach when using GeoGebra (or other dynamic math software) to math problems.

- In math solving, most students do not have the habit of finding different solving strategies. Many mathematicians state that solving math problems in different ways is one of their interests. Asking students to solve a math problem in various ways also contributes to their thinking development and ability to solve problems. With the support of GeoGebra, it is not difficult for students to set up such a task.

\subsection{Implications}

The math solving process of Polya is general. But mathematical solvers have various manipulations with different methods. From the student limitations mentioned above, we propose the following approaches to help teachers and students make efficient use of Polya's process in the case of GeoGebra's assistance (see Table 2) 
Table 2. Finding strategies for solving a problem with the aid of GeoGebra

\begin{tabular}{|c|c|}
\hline Polya's problem solving process & The aid of GeoGebra \\
\hline $\begin{array}{l}\text { Step } 1 \\
\text { Understanding the problem }\end{array}$ & $\begin{array}{l}\text { Using GeoGebra to represent the problem in Figure } \\
\text { - } \\
\text { Determine the question needing to be answered } \\
\text { Calculate the necessary objects (the sum of straight-line segments, the area of some related } \\
\text { objects ...) }\end{array}$ \\
\hline $\begin{array}{c}\text { Step } 2 \\
\text { Devising a plan }\end{array}$ & $\begin{array}{l}\text { Guess } \\
\text { - } \\
\text { Observe Figure to find out relationships between geometric objects and related data (i) } \\
\text { Formulate the conjectures (ii) } \\
\text { Check the conjecture by changing positions of relating factors in the Figure. } \\
\text { - If the conjecture is still valid, then continue to (iii); } \\
\text { Otherwise, go back to (i)\&(ii). Find strategies for solving } \\
\text { Backward analysis: From conjecture, backwards analyzing to what needs to be proved true }\end{array}$ \\
\hline $\begin{array}{c}\text { Step3 } \\
\text { Carrying out the plan }\end{array}$ & $\begin{array}{l}\text { Present the solution } \\
\text { Choose one strategy in Step } 3 \text { to present the solution to the problem }\end{array}$ \\
\hline $\begin{array}{c}\text { Step4 } \\
\text { Looking back }\end{array}$ & $\begin{array}{l}\text { Check the solution } \\
\text { - } \quad \text { Checking solutions, correcting errors } \\
\text { - Generalizing or extending the problem if possible }\end{array}$ \\
\hline
\end{tabular}

In table 2, there are two highlights in step 2, "Guess and Check" and "Backwards analysis."

"Guess and check" includes necessary actions so that the predictions in step 2 are conjectures that need to be proved. Students need to change the shape of the representation of the problem by pressing and dragging related objects to find out invariants of relationships; it helps them confirm conjectures. For example, when considering any triangle, learners have to observe three cases: a right triangle, a triangle with three acute angles, and a triangle with an obtuse angle. In solving math problems with GeoGebra, the solvers can predict the results (conjectures).

The questions are how to do from the conjectures and how to find a solving strategy for the problem. With the intuitive and flexible support of GeoGebra, solvers can use "backwards analysis" tactics to find the strategies for the problem; the tactic can be described as follows:

- If $\mathrm{A}$ is true, then $\mathrm{B}$ must be true;

- If $B$ is true, then $C$ must be true, and so forth;

- $\quad$ Finally, we find what must be proved.

The following are two illustrative examples of using GeoGebra in solving a problem based Polya's process.

\subsubsection{Illustration 1: Finding strategies for solving the $1^{\text {st }}$ problem}

Step 1. Understanding the problem

Based on the given data of Problem 1 and using GeoGebra to draw the representative figure of the problem (Figure 1). Note that A, B and C are the points that can be changed their position by dragging. Therefore, it allows learners to consider the problem with different dimensions, depending on the shape of the $\mathrm{ABC}$ triangle, which is very important for finding invariants-the factors help users to find strategies to solve the problem (Figure 7).

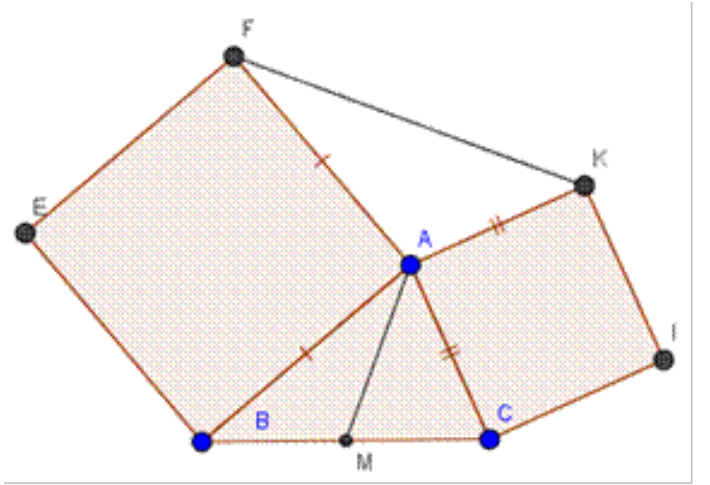

Figure 7. A representative figure of the problem 1

Step 2. Devising a plan

Guess

- Extending segment $A M$ and using a tool for measuring angle, we get the result that $A M \perp F K$ (1)

- $\quad$ Calculating the length of two lines $A M$ and $F K$, from the result given by GeoGebra, we find that $A M=1 / 2$ $F K$ (see Figure 8). (2)

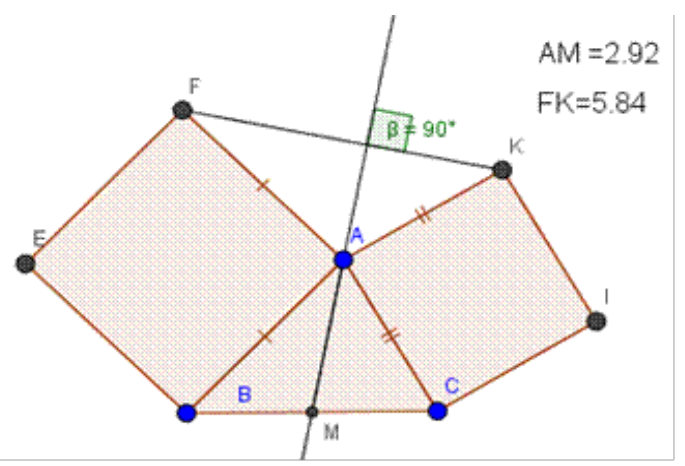

Figure 8. A representative figure of the problem 1

From (1) and (2), we have a rough conjecture: $A M$ is perpendicular to $F K$ and $A M=1 / 2 F K(3)$

Check: To get a correct conjecture, learners need to use 
GeoGebra's dynamics by clicking and dragging one of the three vertices of the triangle $A B C$ to see if (3) is correct in different cases. The result shows that (3) is true even though the shape of the triangle $A B C$ is changed (See Figure 9). Therefore, (3) is the formal conjecture that needs to be proved true with logical arguments.

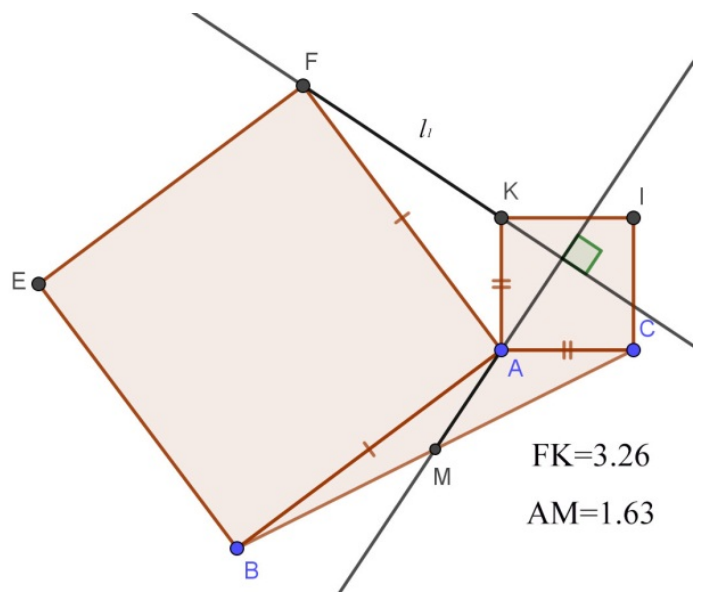

Figure 9. The representative figure of problem $1\left(\angle B A C>90^{\circ}\right)$

\section{Find solving strategies}

Strategy 1: The Conjecture (3) leads to an idea of constructing a triangle in which $A M$ is an average segment.

- From $C$, the line is parallel to $A M$, and it cuts $A M$ extended at $D$.

- Easily prove that the two triangles $\mathrm{CAD}$ and $A K F$ are equal. From this result, we have $C D=F K(=2 A M)$; and by comparing the angles, it is not difficult for us to prove that the $C D$ is perpendicular to $F K$. (see Figure 10)

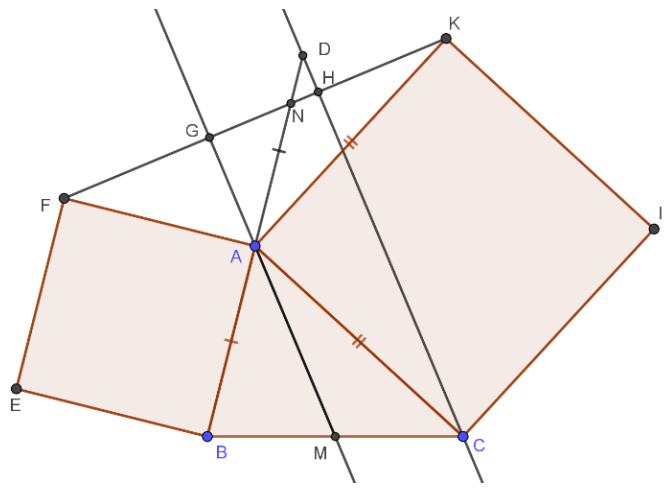

Figure 10. A representative figure of problem 1

Strategy 2: The findings of Strategy 1 imply the application of the rotation around A with an angle of $90^{\circ}$.

Applying the rotation of $90^{\circ}$ (clockwise) about centre $A$, $F K$ is mapped onto $D C$. Then, we have $F K \perp D C$ and $F K$ $=D C=2 A M(A M$ is the midsegment of $\triangle B C D)$. (see Figure 11)

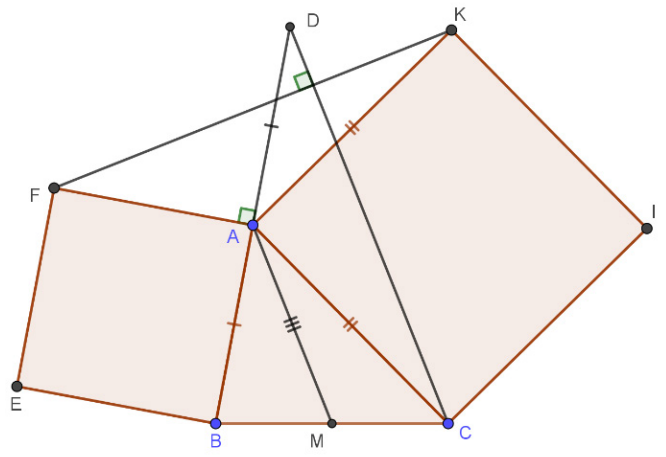

Figure 11. A representative figure of problem 1

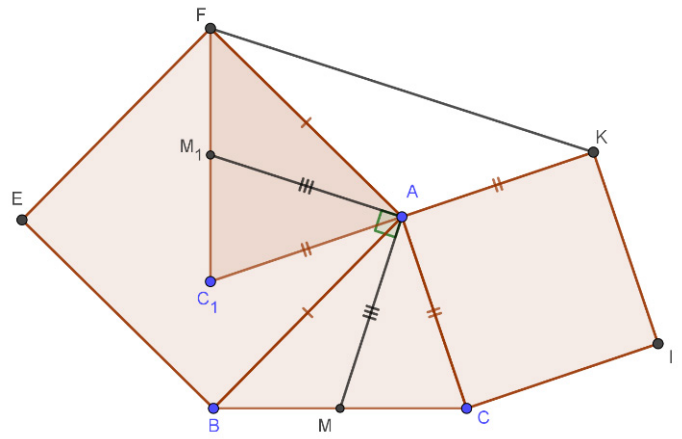

Figure 12. A representative figure of problem 1

Strategy 3: The conjecture (3) and strategy 2 imply a different approach, as follows (Figure 12).

Applying the rotation of $90^{\circ}$ (clockwise) about centre A, then $\triangle \mathrm{AC}_{1}, \mathrm{AM}_{1}$ are the images of $\triangle \mathrm{ACB}$ and $A M$, Therefore, $A M_{1} \perp A M$ and $A M_{1}=A M, A M_{l} / / F K$ and $A M_{l}=$ $1 / 2 F K$. Hence, $A M \perp F K$ and $A M=1 / 2 F K$.

\section{Step 3. Carrying out the plan}

Solution (strategy 2): Let point $D$ be the image of point $\mathrm{B}$ under a rotational symmetry about centre $\mathrm{A}$. Then $A D=$ $A B=A F$ and $A D \perp A F$. A rotation of $90^{\circ}$ about centre $A$ maps line segment $\mathrm{DC}$ onto line segment FK. Therefore, $D C=F K$ and $\mathrm{DC} \perp \mathrm{FK}$. Since AM is the midsegment of triangle $B C D, A M / / C D$ and $\mathrm{AM}=1 / 2 \mathrm{CD}$. Then it is inferred as follows $A M \perp F K$ and $A M=1 / 2 F K$.

\section{Step 4: Developing the problem}

Given a triangle $A B C$. Construct squares $A B E F$ and $A C I K$ outside the triangle. Let (1) be a straight line through A and perpendicular to $F K$. Compare the distance between $B$ and $(l)$ and the one between $A$ and $F K$.

\subsubsection{Illustration 2: Find strategies for solving problem 2}

\section{Step 1: Understanding the problem}

In the Oxy coordinate plane, represent the problem in accordance with the coordinates of the points $A(1,3), B$ $(3,4), C(4,0) . M$ is the point on Ox that can change its position by pressing and dragging. Let $\mathrm{S} 1$ be the area of the $\mathrm{OABC}$ polygon, $\mathrm{S} 2$ be the area of the $O A M$ triangle; $\mathrm{S} 1$ and 
S2 are both displayed on the screen where S2 changes its value as $M$ moves. (Figure 13)

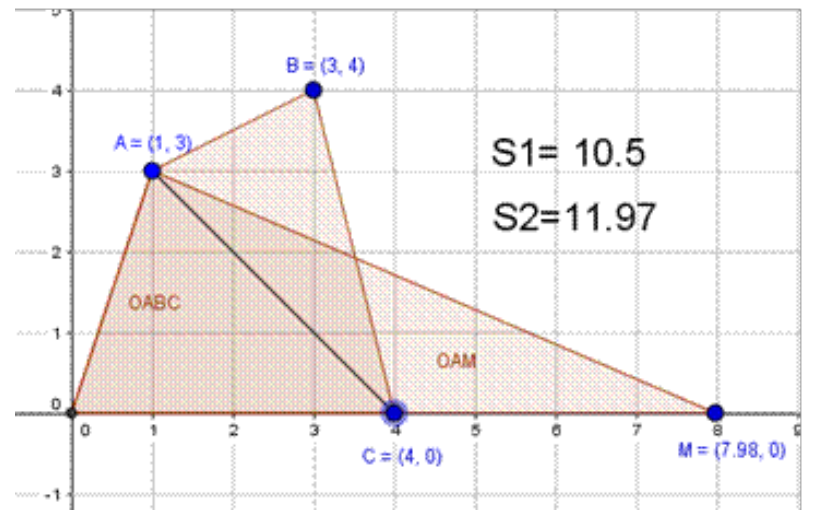

Figure 13. The representative figure of the problem 2

\section{Step 2: Devising a plan}

Guess and check: Do experiment with GeoGebra by using pressing and dragging $M$

Let $M$ move on Ox (by pressing and dragging) to find the position of $M$ such that $S 2=S 1$. After the experiment, the point $M$ to look for is $M(7.0)$.

\section{- Observe data to identify relationships}

Observing Figure 11, we see that $S 1=S 2$ if and only if the area of the triangle $B A C$ is equal to the area of the triangle $M A C$. These two triangles have common $A C$ sides; therefore, the two altitudes of these two triangles $B H$ and $M K$ are equal; it deduces that quadrilateral $B H K M$ is a rectangle and $\mathrm{BM} / / \mathrm{AC}$. Also, $S 1=S 2$ in the case of $M(7,0)$. (Figure 14)

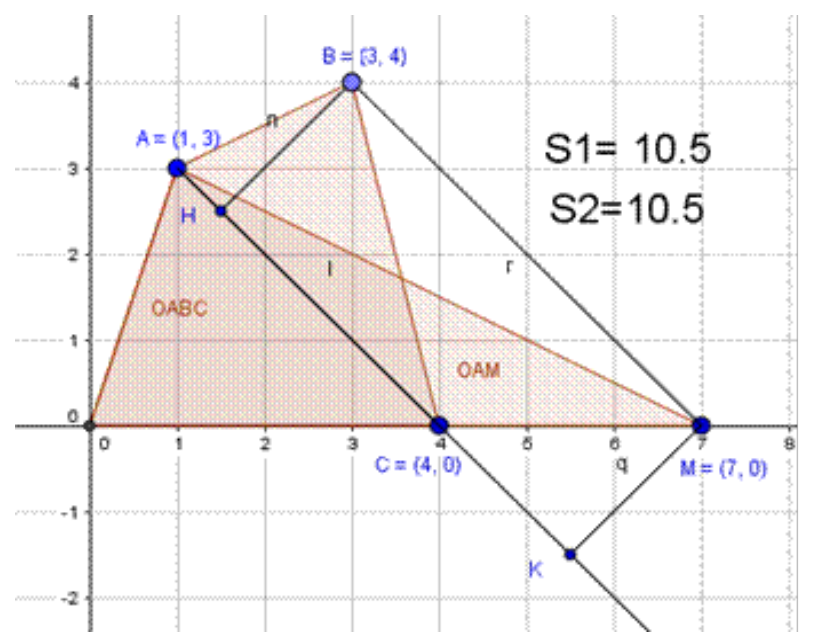

Figure 14. The representative figure of problem 2

\section{- Formulate conjectures (make predictions)}

From the findings obtained from Step 3, we have two conjectures as follows:

The first conjecture: If $M$ has the coordinates $M$ (7.0) then $S 1=S 2$.

The second conjecture: If $B M$ is parallel to $A C$, then $S 1=$

\section{Solving Strategies}

Strategy 1: Let $M(7 ; 0)$ be on Ox. We prove that the distance between $M$ and the straight-line $A C$ is equal to the one between $\mathrm{B}$ and the straight-line $A C$, and we prove that $M(7,0)$ is unique.

Strategy2: Let $M(7 ; 0)$ be on Ox. We prove that $B M / / A C$ and if $N(t, 0)$ where $\mathrm{t} \neq 7$, then $B N$ is not parallel to $A C$.

Strategy 3.: Let $M(m, 0)$. Determine $\mathrm{m}$ such that $B M$ $/ / A C$;

Strategy 4: Let $M(m, 0)$. Determine $m$ such that two vector $\overrightarrow{\mathrm{AC}}$ and $\overrightarrow{\mathrm{BM}}$ the same direction.

Strategy 5: Let $M(m ; 0)$ be on Ox. Determine m such that the distance between $\mathrm{M}$ and the straight-line $A C$ is equal to the one between $\mathrm{B}$ and the straight-line $A C$.

Strategy 6: We construct a straight line $(d)$ such that $(d)$ passes through $B$ and $\mathrm{d} / /(\mathrm{AC})$. The point $\mathrm{M}$ is the intersection of $(d)$ and Ox.

\section{Step 3: Carrying out the plan: Using strategy 4 to present the solution}

\section{Step 4: Developing the problem}

Given the quadrilateral $A B C B$. Determine a point $\mathrm{M}$ on the straight line $A D$ such that the triangle $A B M$ and quadrilateral $A B C D$ have the same area.

\section{Conclusions}

GeoGebra dynamic math software is now one of the most useful software for math teachers at all levels. It can be used in teaching various types of mathematical knowledge and in particular, it supports teachers well in teaching mathematics at schools. Thanks to it, solvers can express problems with flexible representations. By simply clicking and dragging a mathematical object, they can see many aspects of the given problem. Therefore, they easily predict the answer of the problem; i.e. forming relevant conjecture. By backwards analysis, students can know where to start to find strategies for solving a problem asking to prove a mathematical statement is true. Empirical results, however, show that students do not know how to use dynamic mathematical software to solve a problem. In teaching practice, therefore, teachers need to demonstrate the advantages of using GeoGebra in particular, and dynamic math software in general, in finding a problem-solving approach; besides, the teacher should instruct students on how to use backwards analysis to find strategies to deal with problems. As we have already known, the primary tasks of math education are to promote students' creativity, criticism, and develop problem-solving capability. Dynamic math software, such as GeoGebra, will be a great supportive tool for teachers to fulfil the above tasks. S2. 


\section{REFERENCES}

[1] Adoğdu, M. and Ayaz, M.F. (2008). The importance of problem-solving in the mathematics curriculum. e-Journal of New World Sciences Academy, 3(4), 538-545.

[2] Diković, L. (2009). Applications GeoGebra into Teaching Some Topics of Mathematics at the College Level. ComSISVol. 6, No. 2, December 2009, UDC 004.738, DOI: 10.2298 / csis0902191D, 2009

[3] Doğan, M. İçel, R. (2011). The role of dynamic geometry software in the process of learning: GeoGebra example about triangles. International Journal of Human Sciences [Online].8:1. Available: http://www.InsanBilimleri.com/En

[4] Haciomeroglu, E.S. \& Janet, A. (2013). Exploring calculus with dynamic mathematics software. Mathematics and Computer Education, 47 (1), 6-18.

[5] Hao, T.V., Hy. N.M., Anh, K.Q, Thanh, N.H., Vien, P.V (2015). Geometry 11. Vietnam Education Publishing House

[6] Herceg, D., \& Herceg, D. (2010). Numerical integration with GeoGebra in high school. The International Journal for Technology in Mathematics, 17 (4), 205-210.

[7] Hohenwarter, M. \& Preiner, J. (207), Dynamic mathematics with GeoGebra. Journal of Online Mathematics and its Applications. ID 1448, Vol 7, March 2007.

[8] Loc, N.P. \& Nam, T.A.H. (2015). Teaching topic "Ellipse" with the help of mathematics software "GeoGebra": a try out. American International Journal of Research in Science, Technology, Engineering \& Mathematics, 11(1), June-August, 2015. 47-51.

[9] Loc, N.P. (2016). Tích cực hóa hoạt động học tập của học sinh trong dạy hoc môn Toán: Một chuyên khảo trên co sở lý thuyế thoạt động.CầnThơ: NXB Đại học CầnThơ

[10] NCTM (National Council of Teachers of Mathematics) (1980). An agenda for action. Reston, VA: National Council of Teachers of Mathematics.

[11] NCTM (National Council of Teachers of Mathematics) (2000). Principles and Standards for School Mathematics, VA: National Council of Teachers of Mathematics.

[12] Polya, G. (1957). How to solve it, A new aspect of mathematical Method, New York: Doubleday Anchor Books, Doubleday \& Company, Garden City.

[13] Shadaan, P. \& Eu, L.K. (2013) Effectiveness of Using GeoGebra on Circles. The Malaysian Online Journal of Educational Technology, Volume 1, Issue 4, October, 2013 